\title{
Neonatal Chemical Conjunctivitis
}

National Cancer Institute

\section{Source}

National Cancer Institute. Neonatal Chemical Conjunctivitis. NCI Thesaurus. Code C116818.

Inflammation of the conjunctiva in a newborn due to chemical irritation which was acquired postnatally from iatrogenic causes. 